\title{
Mucosal vaccines: the promise and the challenge
}

Marian R. Neutra ${ }^{* \ddagger}$ and Pamela A. Kozlowski*

Abstract | Most infectious agents enter the body at mucosal surfaces and therefore mucosal immune responses function as a first line of defence. Protective mucosal immune responses are most effectively induced by mucosal immunization through oral, nasal, rectal or vaginal routes, but the vast majority of vaccines in use today are administered by injection. As discussed in this Review, current research is providing new insights into the function of mucosal tissues and the interplay of innate and adaptive immune responses that results in immune protection at mucosal surfaces. These advances promise to accelerate the development and testing of new mucosal vaccines against many human diseases including HIV/AIDS.

Mucosal surfaces are enormous surface areas that are vulnerable to infection by pathogenic microorganisms. The adaptive immune system is designed to distinguish antigens, pathogens and vaccines that enter the body through mucosal surfaces from those that are introduced directly into tissues or the bloodstream by injection or injury. It is becoming increasingly clear that local mucosal immune responses are important for protection against disease: for example, mucosal antibodies against Vibrio cholerae bacteria and cholera toxin are associated with resistance to cholera!

Mucosal immune responses are most efficiently induced by the administration of vaccines onto mucosal surfaces, whereas injected vaccines are generally poor inducers of mucosal immunity and are therefore less effective against infection at mucosal surfaces ${ }^{1,2}$. Nevertheless, clinical vaccine research has been based largely on injection of antigens, and most vaccines in use today are administered intramuscularly or subcutaneously. This is understandable because an injection delivers a known quantity of antigen into the body and results in the generation of specific antibodies and lymphoid cells that are readily measured in blood samples. By contrast, our understanding of mucosal immunity and development of mucosal vaccines has lagged behind, in part because administration of mucosal vaccines and measurement of mucosal immune responses are more complicated. The dose of mucosal vaccine that actually enters the body cannot be accurately measured because antibodies in mucosal secretions are difficult to capture and quantitate, and recovery and functional testing of mucosal T cells is labour intensive and technically challenging. As a result, only a few mucosal vaccines have been approved for human use in the United States or elsewhere. These include oral vaccines against poliovirus $^{3}$, Salmonella typhi ${ }^{1}$, V. cholerae ${ }^{1}$ and rotavirus ${ }^{4}$, and a nasal vaccine against influenza virus ${ }^{5}$. However, research and testing of mucosal vaccines is currently accelerating, stimulated by new information on the mucosal immune system and by the threat of the mucosally transmitted virus, $\mathrm{HIV}^{6,7}$.

In this Review, we provide an overview of the events within mucosal tissues that lead to protective mucosal immune responses, and we consider key biological and technical aspects of mucosal vaccine design. We then summarize current progress in the development of mucosal vaccines against HIV.

\section{Mechanisms of mucosal protection}

Innate defences at mucosal surfaces. Mucosal surfaces of the respiratory, gastrointestinal and urogenital tracts are separated from the outside world by delicate epithelial barriers. In the gastrointestinal tract, for example, a single layer of epithelial cells joined by tight junctions faces a complex luminal environment that is rich in microorganisms. Epithelia and their associated glands (such as the salivary glands) produce nonspecific or innate defences including mucins and antimicrobial proteins ${ }^{8}$. Nevertheless, foreign antigens and microorganisms frequently breach the epithelial barrier and mucosal tissues are sites of intense immunological activity. In the intestinal mucosa, dispersed lymphoid and antigen-presenting cells are particularly abundant; 
Antibody-dependent cell-mediated cytoxicity (ADCC). A mechanism by which natural killer cells are targeted to antibody-coated cells, resulting in the lysis of the antibody-coated cells. it has been estimated that there are more antibodyproducing cells in the intestinal mucosa than in the spleen and lymph nodes combined ${ }^{9,10}$.

Epithelial cells are active participants in mucosal defence. They function as sensors that detect dangerous microbial components through patternrecognition receptors such as Toll-like receptors (TLRs). They respond by sending cytokine and chemokine signals to underlying mucosal cells, such as dendritic cells (DCs) and macrophages, to trigger innate, nonspecific defences and promote adaptive immune responses ${ }^{8,11,12}$. In the intestine, where bacteria are abundant, epithelial cells, together with intraepithelial lymphocytes and underlying phagocytic cells, can modulate and dampen these signals to prevent undesirable responses to nonthreatening nutrients and the normal intestinal flora that could lead to mucosal inflammation ${ }^{13-15}$. Therefore, mucosal tissues are in a constant state of alert, but they are adapted to the presence of foreign microorganisms and their products. As a result, vaccines that would produce vigorous immune responses if injected into a

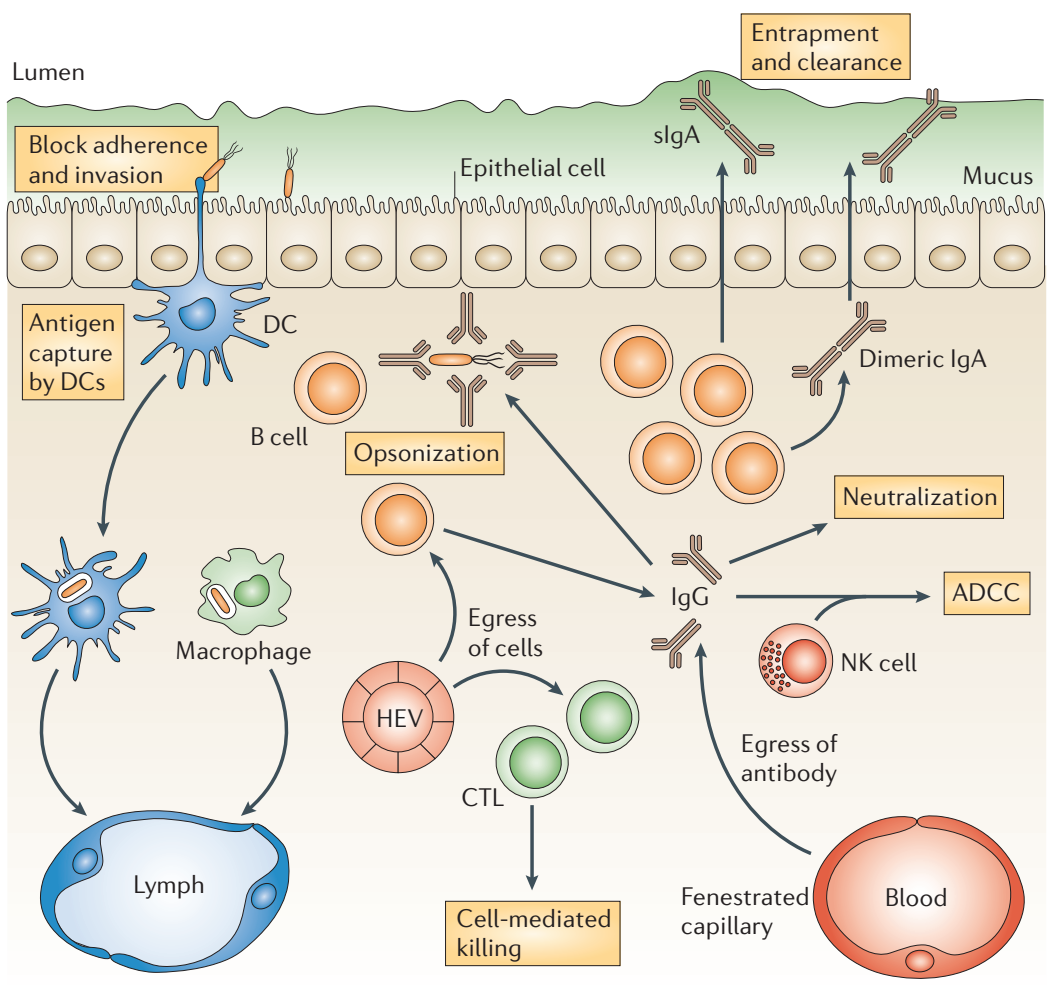

Figure 1 | Mechanisms of immune protection at mucosal surfaces. Multiple immune effector mechanisms contribute to protection at mucosal surfaces. Antigen-specific effector $B$ and T cells in the bloodstream recognize mucosal high endothelial venules (HEVs) and enter the mucosa. Mucosal B cells terminally differentiate to become mucosal plasma cells, most of which produce dimeric $\lg \mathrm{A}$ that is exported into secretions as secretory $\lg A(\operatorname{sg} A)$ to intercept antigens and pathogens, and to prevent mucosal invasion. Neutralizing $\lg G$ is also present within mucosal tissues; mucosal lgG might be derived from local plasma cells or from blood, by diffusion from local fenestrated capillaries. Infected cells might be killed by specific cytotoxic T lymphocytes (CTLs) or by antibody-dependent cell-mediated cytotoxicity (ADCC), a collaboration between natural killer (NK) cells and antibodies. Pathogens can also be captured by dendritic cells (DCs) and macrophages, and carried to draining lymph nodes. sterile environment, such as muscle, might be 'ignored' when given mucosally, where the tissue is constantly exposed to microorganisms.

Adaptive immune protection at mucosal surfaces. Diverse strategies are used by mucosal pathogens to infect humans. Some pathogens such as V. cholerae and enteropathogenic Escherichia coli cause disease by colonizing epithelial surfaces. Pathogens such as rotavirus and influenza virus infect the epithelium, whereas others such as Shigella flexneri and S. typhimurium establish local infection in the lamina propria. Other pathogens, including HIV and S. typhi, use the intestinal mucosa as a staging area for systemic spread of infection. Protection against such diverse threats involves multiple immune effector strategies that operate on both sides of the epithelial barrier (FIG. 1).

An important characteristic of the mucosal adaptive immune response is the local production and secretion of dimeric or multimeric immunoglobulin A (IgA) antibodies that, unlike other antibody isotypes, are resistant to degradation in the protease-rich external environments of mucosal surfaces. In humans, more $\operatorname{IgA}$ is produced than all the other immunoglobulin isotypes combined ${ }^{10}$, and high concentrations of IgA antibodies (over $1 \mathrm{mg}$ per $\mathrm{ml}$ ) are present in the secretions that are associated with mucosal surfaces in normal humans ${ }^{16,17}$. The protease resistance of secretory $\operatorname{IgA}(\operatorname{sg} A)$ is a result of its dimerization and high degree of glycosylation during its synthesis in mucosal plasma cells ${ }^{18}$, and its association with a glycosylated fragment (the secretory component) derived from the epithelial polymeric immunoglobulin receptor ( $\mathrm{pIgR}$ ) that mediates transport of dimeric IgA across epithelial cells to the lumen ${ }^{19}$.

sIgA has multiple roles in mucosal defence ${ }^{2}$. It promotes the entrapment of antigens or microorganisms in the mucus, preventing direct contact of pathogens with the mucosal surface, a mechanism that is known as 'immune exclusion'. Alternatively, sIgA of the appropriate specificity might block or sterically hinder the microbial surface molecules that mediate epithelial attachment ${ }^{20}$, or it might intercept incoming pathogens within epithelial-cell vesicular compartments during pIgR-mediated transport ${ }^{2,19}$. Interstitial fluids of mucosal tissues that underlie the epithelial barrier contain dimeric $\operatorname{IgA}$ that is synthesized by local IgA-secreting plasma cells and this might prevent mucosal-cell infection, by mediating the transport of pathogens that have breached the epithelial barrier back into the lumen through $\mathrm{pIgR}^{21}$ or by mediating antibody-dependent cell-mediated cytotoxicity (ADCC) that leads to the destruction of local infected cells ${ }^{10,22}$.

Local IgG synthesis also can occur in the mucosal tissues following the administration of antigen or vaccine to mucosal surfaces ${ }^{17,18,23,24}$. Large numbers of IgG-secreting plasma cells are present in the female genital tracts of macaques and humans ${ }^{23}$, and high concentrations of IgG as well as IgA have been measured in human cervical and vaginal secretions ${ }^{17,18}$. This IgG, as well as sIgA, could play a significant role in blocking infection by sexually transmitted pathogens at this site, 


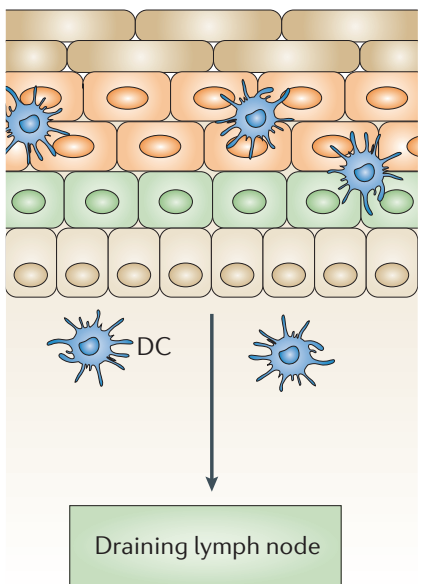

Nose and airways

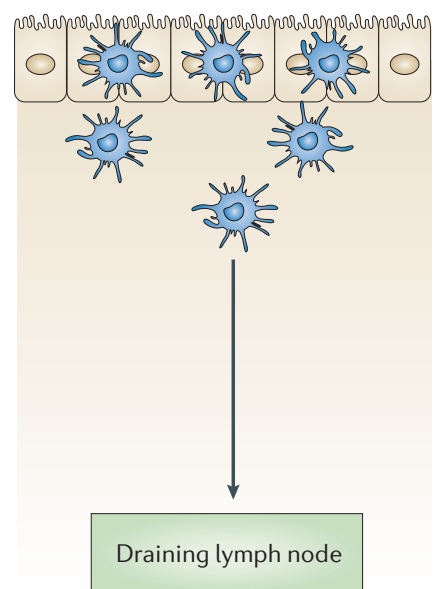

Follicle-associated epithelium: small intestine, colon, rectum, tonsils and adenoids

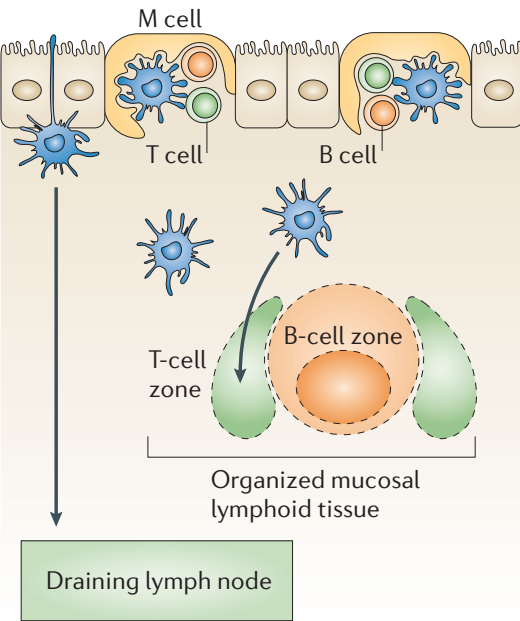

Figure 2 | Antigen sampling at mucosal surfaces: collaboration of epithelial cells and dendritic cells. Antigen sampling strategies are adapted to the diverse epithelial barriers that cover mucosal surfaces throughout the body, but all involve collaboration with dendritic cells (DCs). DCs might congregate immediately under epithelia, migrate into the epithelial layer, and even extend dendrites into the lumen to capture antigens. DCs from any mucosal surface might travel to the nearest draining lymph node to present antigen to T cells. At sites of organized mucosal lymphoid tissues, specialized microfold (M) cells in the lymphoid follicle-associated epithelium deliver antigens across the epithelial barrier directly to subepithelial DCs that then present antigen locally in adjacent mucosal T-cell areas.

as has been shown for infection with herpes simplex virus type 2 in mice ${ }^{25}$. Concentrations of IgG and IgA in secretions of the female reproductive tract are affected by hormonal signals and change dramatically during the menstrual cycle ${ }^{24}$, and this might be an important factor in the effectiveness of mucosal vaccines against sexually transmitted diseases. In the human intestine, $5-15 \%$ of mucosal plasma cells secrete IgG ${ }^{9}$, but IgG is susceptible to degradation by luminal intestinal and bacterial proteases. In large intestinal secretions, for example, IgG concentrations are generally 30 - to 100 -fold lower than those of sIgA ${ }^{26}$. Nevertheless, intact IgG in mucosal tissues, whether locally produced or from serum, can potentially neutralize pathogens that enter the mucosa and prevent systemic spread.

It is often assumed that mucosal or serum IgG diffuses across epithelial barriers and into secretions by paracellular leakage. However, receptor-mediated IgG transport might also occur. Recent studies have shown that an IgG-specific Fc receptor (neonatal Fc receptor, FcRn) is expressed by epithelial cells in the intestine and airways, and can mediate IgG transport in both directions across epithelial barriers ${ }^{27}$. Therefore, this system might export IgG, and might also mediate the uptake of antigens into the mucosa ${ }^{27}$. In addition, a new IgAspecific receptor has been identified on apical surfaces of microfold cells ( $M$ cells) that can mediate uptake of luminal IgA into Peyer's patches ${ }^{28}$. The immunological significance of these uptake mechanisms has yet to be determined, but there is some evidence that they might facilitate the sampling of luminal immune complexes by the mucosal immune system ${ }^{27,29}$.

Cytotoxic T lymphocytes (CTLs) in mucosal tissues cannot prevent pathogen entry, but they might have a crucial role in clearance or containment of mucosal viral infections. For example, mucosally immunized (but not systemically immunized) mice were protected against infection after mucosal challenge with a recombinant vaccinia virus expressing HIV glycoprotein 160 (gp160), but this protection was abrogated by treatment of the mice with CD8-specific antibodies ${ }^{30}$. Immunologically active mucosal tissues, such as the intestinal tract, contain abundant $\mathrm{CD} 4^{+} \mathrm{T}$ cells that are targets for HIV. As a result, the intestinal mucosa becomes a reservoir of HIV infection regardless of the site of initial viral entry ${ }^{31,32}$. Both CTLs and antibodies within mucosal tissues might contribute to preventing the establishment of such mucosal reservoirs.

\section{Induction of mucosal immune responses}

Antigen sampling at mucosal surfaces. The induction of mucosal immune responses against foreign antigens, microorganisms and vaccines requires the presence of organized lymphoid tissue, either within the mucosa or in draining lymph nodes ${ }^{9}$ (FIG. 2). Organized mucosal inductive sites are concentrated in areas where pathogens are most likely to enter the body (for example, the palatine and lingual tonsils and adenoids in the oral and nasopharyx) and at sites of high microbial density (such as the lower intestinal tract). In humans, aggregates of organized mucosal lymphoid follicles form the Peyer's patches in the distal ileum, and abundant isolated follicles are present in the appendix, colon and rectum ${ }^{33}$. The presence of a mucosal lymphoid follicle influences the overlying epithelium by inducing differentiation of a specialized follicle-associated epithelium (FAE), which contains $\mathrm{M} \mathrm{cells}^{34}$. M cells form intraepithelial pockets into which lymphocytes migrate, and they deliver samples of foreign material by vesicular transport from the intestinal lumen directly into the pocket and to underlying DCs. 
In the intestine, the entire FAE is distinct from the absorptive epithelium that lines the vast majority of the intestinal surface area $^{34}$. The FAE of a mouse smallintestinal Peyer's patch produces chemokines, including CC-chemokine ligand 20 (CCL20; also known as MIP3 $\alpha$ ) and CCL9 (also known as MIP1 $\gamma$ ), that attract lymphocytes and DCs that express CC-chemokine receptor 6 (CCR6) or CCR1, respectively ${ }^{35-37}$. Attraction of DCs to the FAE results in a high density of phagocytic cells at sites of entry of foreign antigens and pathogens, presumably to promote local antigen sampling and minimize the likelihood of systemic infection (FIG. 3). Particles and live bacteria that are transported across the FAE by $M$ cells can be captured by DCs in the subepithelial dome (SED) regions of Peyer's patches in mice ${ }^{38,39}$. DCs in the SED region are phenotypically immature, but after antigen capture they migrate to adjacent interfollicular T-cell zones (FIG. 4), where they upregulate the expression of maturation markers and MHC molecules ${ }^{39,40}$. Some Peyer's patch DCs might also carry antigen to draining lymph nodes, where they interface with the systemic immune system ${ }^{41}$.

In the absence of organized mucosal lymphoid tissues, antigens and pathogens might also be sampled on mucosal surfaces through another type of epithelial-DC collaboration. Throughout stratified, pseudostratified and simple epithelia, motile DCs can migrate into the narrow spaces between epithelial cells and even to the outer limit of the epithelium ${ }^{42-44}$, where they can obtain samples of foreign material directly from the luminal compartment (FIG. 2). This might be most immunologically significant at mucosal locations such as the female genital tract, where there are no organized lymphoid follicles and the epithelium lacks M cells. Intraepithelial and subepithelial DCs that have captured pathogens could potentially interact with local lymphocytes to stimulate

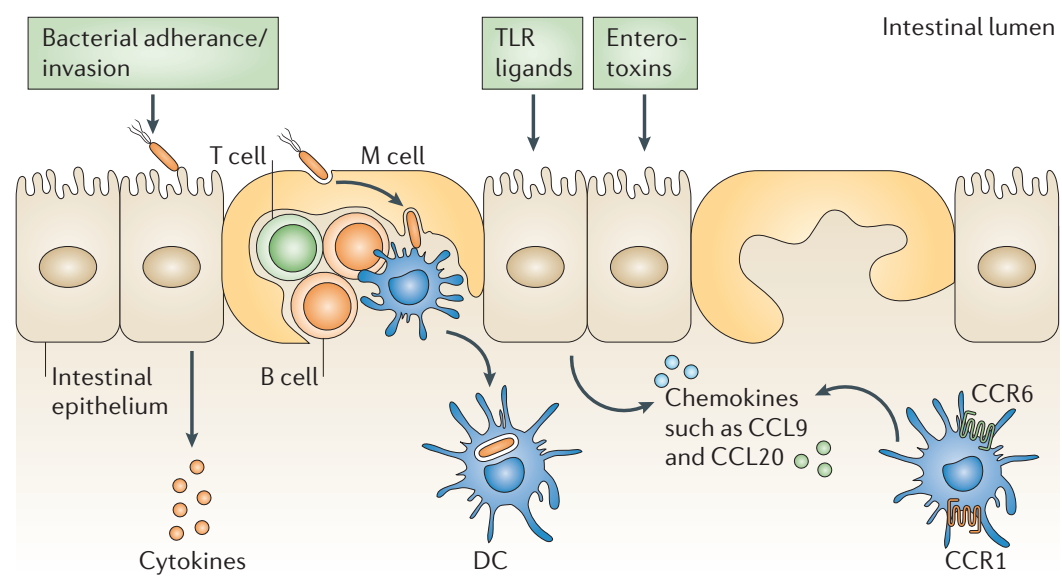

Figure 3 | Functions of the follicle-associated epithelium. The follicle-associated epithelium (FAE) contains microfold (M) cells that are specialized for endocytosis and rapid transepithelial transport of intact antigens and microorganisms into intraepithelial pockets that contain B and $T$ cells and occasional dendritic cells (DCs). The majority of FAE cells are enterocytes with apical microvilli coated by a thick brush border glycocalyx. FAE enterocytes do not transport antigens, but they might contribute to antigen sampling by sensing luminal pathogens and their products and releasing cytokine and chemokine signals that attract and activate DCs. CCL, CC-chemokine ligand; CCR, CC-chemokine receptor; TLR, Toll-like receptor. memory responses ${ }^{45}$ or immune tolerance ${ }^{46}$, or they could exit the mucosa through lymphatics to present antigens to naive $\mathrm{T}$ cells in organized lymphoid tissues of draining lymph nodes ${ }^{41}$. There is evidence that different subpopulations of DCs have distinct roles in determining the nature of immune responses in vivo, including those in the Peyer's patches ${ }^{40}$. In addition, much remains to be learned about DC migration patterns. For example, transcutaneous immunization can result in mucosal immune responses, and DCs from skin have been found to migrate to Peyer's patches ${ }^{47}$.

Focusing the mucosal immune response. $\mathrm{B}$ and $\mathrm{T}$ cells that are activated in organized mucosal lymphoid tissues upregulate the expression of tissue-specific adhesion molecules and chemokine receptors that function as 'homing receptors' to guide the lymphocytes back to the mucosa through recognition of endothelial counter-receptors in the mucosal vasculature ${ }^{48,49}$. Some of these receptors and chemokines are broadly expressed or exhibit redundancy. For example, IgAsecreting B cells that are activated in mucosa-associated organized lymphoid tissues express CCR10, the receptor for CCL28, which is secreted by epithelial cells throughout the small and large intestines, salivary glands, tonsils, respiratory tract and lactating mammary glands ${ }^{48}$. Therefore, CCR $10^{+} \operatorname{Ig} \mathrm{A}^{+} \mathrm{B}$ cells can be attracted to all of these tissues. This broad recognition system explains why mucosal immunization at one site can result in the secretion of specific IgA antibodies in other mucosal or glandular tissues; this is referred to as the 'common mucosal immune system' ${ }^{50}$.

As well as this common system, however, there are receptor-mediated recognition systems that serve to focus the immune response at the site where an antigen or pathogen was initially encountered. For example, $\operatorname{IgA}^{+} \mathrm{B}$ cells that are generated in intestinal inductive sites enter the bloodstream, but they preferentially migrate back into the intestinal mucosa because they express the homing receptor $\alpha_{4} \beta_{7}$-integrin that interacts strongly with MADCAM1, an 'addressin' that is expressed by venules in the small and large intestine (and lactating mammary glands) but not in other mucosal tissues $^{48}$. Circulating $\alpha_{4} \beta_{7}$-integrin-expressing $\mathrm{T}$ cells that are activated in the small intestine also express CCR9, which attracts them to CCL25, a chemokine that is secreted by epithelial and perhaps endothelial cells of the small (but not large) intestine $\mathrm{e}^{51}$. Additional soluble factors that are synthesized by epithelial cells, DCs and other cells at sites of vaccination, infection or inflammation can upregulate the expression of addressins by local endothelial cells ${ }^{52}$ and also probably dictate the patterns of homing molecules expressed by locally activated $\mathrm{T}$ cell $\mathrm{s}^{53}$. For example, interleukin-12 (IL-12)-mediated upregulation of P-selectin glycoprotein ligand 1 expresion by $\mathrm{CD}^{+}$ T cells that are activated in Peyer's patches was recently linked to the entry of $\mathrm{T}$ helper $\left(\mathrm{T}_{\mathrm{H}}\right)$ cells to the smallintestinal lamina propria ${ }^{54}$. The regional nature of mucosal immune responses has been clearly shown in non-human primates and humans (TABLE 1). 


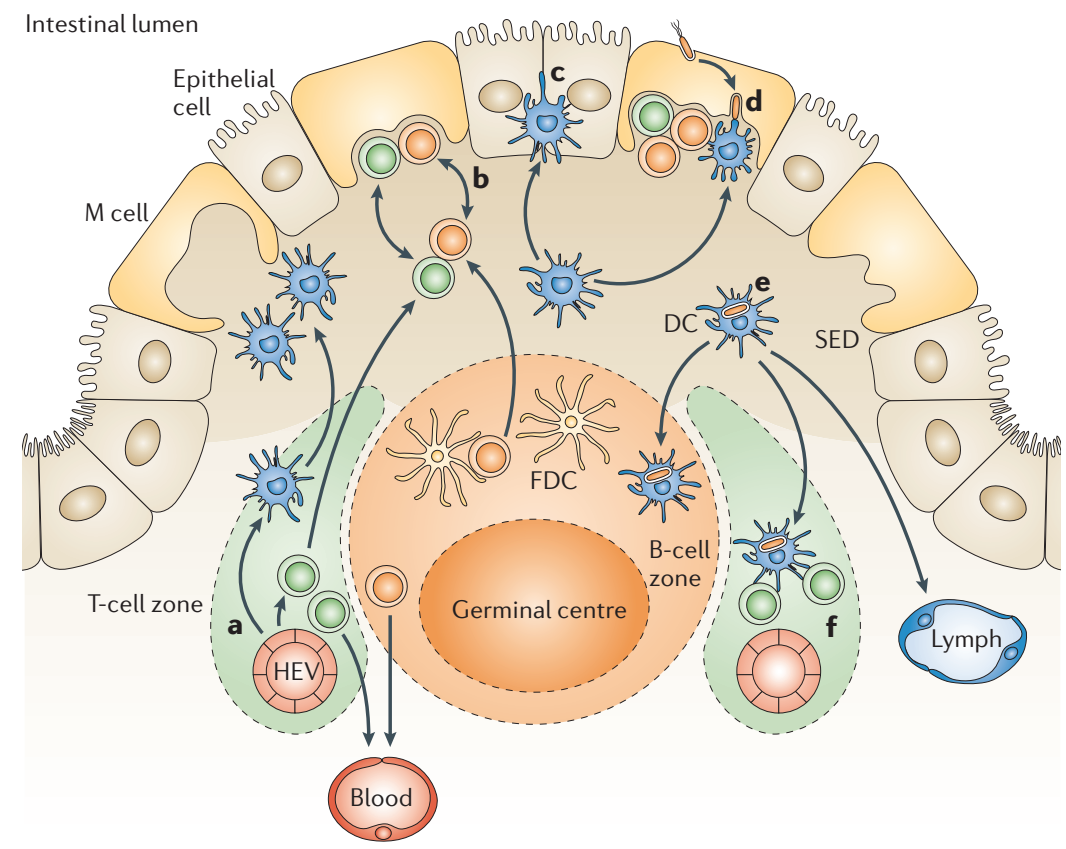

Figure 4 | Cellular traffic in organized mucosal lymphoid tissues. The

choreography of cellular movements in organized mucosal lymphoid tissues is complex and only partly understood. A simplified version based on studies of Peyer's patches is shown here; for more details refer to the text and REFS 40,48. a | Naive and memory lymphocytes as well as immature dendritic cells (DCs) enter the mucosa through high endothelial venules (HEVs). Some of these cells are attracted to the subepithelial dome (SED) region by chemokines released from the follicle-associated epithelium (FAE). b | Some B and T cells migrate into microfold (M)-cell pockets, where they express maturation or memory markers. $\mathbf{c}$ | Most immature DCs remain in the SED region but a few migrate into the FAE. $\mathbf{d} \mid$ Antigens and microorganisms transported by $\mathrm{M}$ cells are captured by DCs. e | Antigen capture along with other signals induces DC maturation and movement into interfollicular T-cell areas, the B-cell zone, and perhaps into draining lymphatics. $\mathbf{f} \mid$ In interfollicular areas, DCs process and present antigen to naive T cells. FDC, follicular dendritic cell.

Mucosal immunization routes also can induce the production of serum IgA and IgG because a fraction of the B cells that are activated in the mucosa or in the draining lymph nodes express the peripheral homing receptors, $\alpha_{4} \beta_{1}$-integrin and leukocyte (L)-selectin ${ }^{48}$. In addition, mucosal DCs can migrate and carry antigen to systemic inductive sites such as the lymph nodes and spleen $^{41}$. By contrast, systemic immunization is generally ineffective for the induction of mucosal IgA antibody responses because expression of CCR10, $\alpha_{4} \beta_{7}$-integrin and other mucosal homing receptors is not induced on $\mathrm{B}$ cells that are activated in the peripheral lymph nodes ${ }^{48}$. $\mathrm{CD}^{+} \mathrm{T}$ cells that are activated in response to mucosal antigen might initially have a fairly unrestricted migration pattern, but in the long term, memory $\mathrm{CD}^{+} \mathrm{T}$ cells show a preference for the tissue in which antigen was originally encountered ${ }^{55}$.

What is the best immunization route? Ideally, vaccination at a single site would provide both humoral and cell-mediated protection, not only at the relevant mucosal surface, but also throughout the body. In this regard, nasal vaccination has shown particular potential. In mice, monkeys and humans, nasal administration of vaccines has induced specific mucosal $\operatorname{IgA}$ antibody responses in the salivary glands, upper and lower respiratory tracts, male and female genital tracts, and the small and large intestines ${ }^{17,56-58}$. The nasal route can also induce CTLs in distant mucosal tissues including the female genital tract ${ }^{59}$. In addition, nasal immunization studies in humans and mice produced greater systemic antibody responses than other mucosal immunization routes ${ }^{17,56}$, presumably because antigens or antigen-presenting cells were readily trafficked to draining lymph nodes from this site. In mice and monkeys, nasal immunization with certain live viral vectors generated systemic antiviral CTLs and IgG at concentrations that were comparable to those induced by parenteral vaccination routes ${ }^{60,61}$. However, rectal immunization of mice with a non-living peptidebased vaccine was more effective than nasal or oral routes at inducing systemic $\mathrm{CTLs}^{62}$. Taken together, the evidence suggests that the choice of mucosal vaccination route requires consideration of the species, the nature of the vaccine and the expected site of challenge. Although nasal immunization might be particularly effective for protection against respiratory pathogens, optimal protection of the gastrointestinal tract, the rectum and female genital tract might still require oral, rectal or vaginal vaccines (TABLE 1). However, the response to vaginal vaccines might be affected by the stage of the menstrual cycle during which immunization is carried out ${ }^{17}$.

For many pathogens, optimal protection is likely to require both mucosal and systemic immune effectors, and the most effective mucosal vaccine strategies might be prime-boost combinations that involve both mucosal and systemic delivery. Which should come first? There is evidence that in naive human vaccine recipients, mucosal immunization can prime the immune system for both systemic and mucosal responses, presumably by inducing the expression of both mucosal and systemic homing receptors by responding lymphocytes ${ }^{48}$. By contrast, parenteral priming might not prime the immune system for subsequent mucosal vaccination ${ }^{50}$.

\section{Challenges in mucosal vaccine design}

Mucosal vaccines that are given orally or deposited directly on mucosal surfaces face the same gauntlet of host defences as do microbial pathogens: they are diluted in mucosal secretions, captured in mucus gels, attacked by proteases and nucleases, and excluded by epithelial barriers. So, relatively large doses of vaccine are required and it is impossible to determine exactly what dose actually crosses the mucosa. Soluble, nonadherent antigens are taken up at low levels, if at all, and in the intestine, such antigens generally induce immune tolerance ${ }^{46}$. The vaccine formulations and delivery strategies that have been used to address these challenges have been reviewed elsewhere ${ }^{63}$. In general, mucosal vaccines are likely to be most effective when they mimic successful mucosal pathogens in key respects: they would ideally be multimeric and/or particulate, adhere to mucosal surfaces (or even better, adhere selectively to $\mathrm{M}$ cells), efficiently stimulate innate responses, and evoke adaptive immune responses that are appropriate for the target pathogen. 


\begin{tabular}{|c|c|c|c|c|c|c|c|c|}
\hline \multirow[t]{2}{*}{ Immunogen } & \multirow[t]{2}{*}{ Route } & \multirow{2}{*}{$\begin{array}{l}\text { Specific } \\
\text { serum IgG }\end{array}$} & \multicolumn{5}{|c|}{ Responses of specific IgA antibodies* } & \multirow[t]{2}{*}{ References } \\
\hline & & & $\begin{array}{l}\text { Small } \\
\text { intestine }\end{array}$ & $\begin{array}{l}\text { Large } \\
\text { intestine }\end{array}$ & $\begin{array}{l}\text { Cervix/ } \\
\text { vagina }\end{array}$ & $\begin{array}{l}\text { Salivary } \\
\text { glands }\end{array}$ & $\begin{array}{l}\text { Nasal } \\
\text { cavity }\end{array}$ & \\
\hline $\begin{array}{l}\text { Cholera toxin } \\
\text { B subunit }\end{array}$ & $\begin{array}{l}\text { Nasal } \\
\text { Oral } \\
\text { Rectal } \\
\text { Vaginal }\end{array}$ & $\begin{array}{l}+++++ \\
+++ \\
+++ \\
++\end{array}$ & $\begin{array}{l}\text { ND } \\
++++ \\
\text { ND } \\
\text { ND }\end{array}$ & $\begin{array}{l}++ \\
++ \\
++++ \\
+/-\end{array}$ & $\begin{array}{l}+++ \\
+/- \\
- \\
+++\end{array}$ & $\begin{array}{l}- \\
+ \\
+/- \\
+/-\end{array}$ & $\begin{array}{l}+++ \\
- \\
\text { ND } \\
\text { ND }\end{array}$ & $\begin{array}{r}16,17 \\
114-116\end{array}$ \\
\hline $\begin{array}{l}\text { Live } \\
\text { attenuated } \\
\text { Salmonella } \\
\text { typhi Ty21a }\end{array}$ & $\begin{array}{l}\text { Oral } \\
\text { Rectal }\end{array}$ & $\begin{array}{l}++ \\
+\end{array}$ & $\begin{array}{l}+++ \\
+/-\end{array}$ & $\begin{array}{l}- \\
++\end{array}$ & $\begin{array}{l}+/- \\
-\end{array}$ & $\begin{array}{l}+/- \\
-\end{array}$ & $\begin{array}{l}- \\
+1-\end{array}$ & 117,118 \\
\hline $\begin{array}{l}\text { Poliovirus } \\
\text { vaccine }\end{array}$ & $\begin{array}{l}\text { Oral } \\
\text { Colonic } \\
\text { Vaginal }\end{array}$ & $\begin{array}{l}++++ \\
++++ \\
-\end{array}$ & $\begin{array}{l}+++ \\
\text { ND } \\
\text { ND }\end{array}$ & $\begin{array}{l}++ \\
+++ \\
\text { ND }\end{array}$ & $\begin{array}{l}- \\
\mathrm{ND} \\
+++\end{array}$ & $\begin{array}{l}\text { ND } \\
\text { ND } \\
\text { ND }\end{array}$ & $\begin{array}{l}+ \\
- \\
-\end{array}$ & 119,120 \\
\hline
\end{tabular}

Breaching the epithelial barrier. The effectiveness of live pathogens as mucosal vaccines and vaccine vectors is partly a result of their adaptation to survive in lumenal environments and to efficiently invade organized mucosal lymphoid tissues. Indeed, two of the most effective oral vaccines, live attenuated poliovirus ${ }^{3}$ and live attenuated $S$. typhi $i^{1}$, are derived from pathogens that preferentially adhere to $\mathrm{M}$ cells and exploit M-cell transport to invade organized mucosal lymphoid tissues in the intestine ${ }^{64,65}$. The efficiency of non-living mucosal vaccines is unlikely to be comparable to these successful invaders, but uptake into the mucosa can be significantly increased. Protein, peptide and DNA vaccines as well as live vaccines can be partially protected from degradation by oral delivery in enteric-coated gelatin capsules ${ }^{1}$ or by inclusion in copolymeric microparticles ${ }^{66}$, liposomes ${ }^{67}$ or proteosomes ${ }^{68}$. The retention of vaccine antigens on mucosal surfaces by delivery in adherent gel-forming polymers, such as chitosan, has been shown to increase antigen uptake and immune responses ${ }^{69}$. The coupling of antigen with proteins that themselves are adherent to epithelial surfaces has also enhanced mucosal immune responses, presumably by promoting adherence and entry into epithelial-cell transport pathways ${ }^{34}$.

Particulate vaccines have several theoretical advantages for mucosal delivery. M cells are particularly accessible to microparticles and actively transport them into Peyer's patches. Microparticles that are are small (up to $1 \mu \mathrm{m}$ diameter) and adherent to $\mathrm{M}$ cells are taken up most efficiently ${ }^{34,70,71}$. Ligands and antigens can therefore be targeted to Peyer's patches by association with microparticles. Particulate vaccines that enter mucosal inductive sites have the additional advantage of being readily taken up by mucosal DCs and providing antigen depots. Virus-like particles ${ }^{72,73}$ and small vesicles derived from bacterial outer-membrane components ${ }^{68,74}$ are particularly promising as mucosal vaccines because their size is appropriate for uptake by M cells and DCs, their surface structures mimic those of mucosal pathogens, and they can activate an innate immune response. In practice, however, large amounts are needed for mucosal immunization because microparticles tend to be trapped in mucus and only a small fraction of the administered dose is likely to enter mucosal inductive sites.

Alerting the mucosal immune system. Non-living macromolecules, protein-subunit antigens and non-microbial particles generally evoke weak or undetectable adaptive immune responses when applied mucosally. To be distinguished from harmless substances and nutrients, mucosal vaccines must raise alarms in the mucosa by including substances that activate innate signalling pathways in epithelial cells and/or in the underlying antigen-presenting cells. The best-known mucosal adjuvants are the secreted enterotoxins of $V$. cholerae and E. coli, cholera toxin and E. coli heat-labile enterotoxin $^{75}$. As microgram oral doses of these toxins induce severe diarrhoea in humans, several genetically modified forms have been engineered to reduce or eliminate the toxicity associated with the enzymatic A subunits of these toxins $\mathrm{s}^{75}$. Interest in mutated toxins as adjuvants for nasal vaccines has been dampened by the observation of B-subunit-dependent retrograde transport to the brain by olfactory nerves in experimental animals ${ }^{76}$ and association with adverse neurological effects in humans ${ }^{77}$. Recently, alternative chimeric toxins that couple an enzymatic A subunit with more restricted cell-targeting molecules show promise for safe nasal use in humans ${ }^{78}$.

Meanwhile, new information about the functions of immunomodulatory cytokines in mucosal immunity and the discovery of TLRs have provided promising new alternatives. For example, there is evidence that mucosal immune responses to vaccines can be increased by the incorporation of cytokines such as IL-12, granulocyte/ macrophage colony-stimulating factor (GM-CSF) or a combination of both ${ }^{79}$. Various TLR ligands including CpG-containing oligonucleotides ${ }^{80}$, flagellin ${ }^{81}$ and bacterial porins ${ }^{68}$ have shown adjuvant activity when administered mucosally together with antigens. TLR ligands and toxins function as mucosal adjuvants, presumably because they activate key innate signalling pathways 
and stimulate the appropriate mucosal DCs that in turn orchestrate adaptive immune responses that are designed for defence against live pathogens.

Many live attenuated mucosal vaccine vectors, including poliovirus, adenovirus and enteric bacteria, are currently under development and have been extensively reviewed $^{1,82}$. The superiority of live attenuated pathogens as mucosal vaccines and vaccine vectors is due in part to their ability to activate multiple innate responses, and the importance of innate immunity in the development of adaptive immune responses is becoming increasingly clear. Nevertheless, some live vaccines present safety and acceptability issues that might reflect innate immune responses and inflammation, such as mild enteritis-like symptoms in the case of oral administration of certain live attenuated bacteria ${ }^{1}$. An additional concern for live nasal vaccines is the possibility of retrograde transport to the brain through olfactory nerves, as has been found with live attenuated adenovirus ${ }^{83}$. Live vaccine vectors and adjuvants that cannot be used orally or nasally might be safe and effective if administered by the rectal or vaginal route, however, and this possibility warrants testing in human studies.

\section{Developing a mucosal vaccine for HIV}

The role of mucosal immunity in protection against HIV. HIV might be considered as a mucosal pathogen, because transmission occurs mainly through exposure of mucosal surfaces to HIV and HIV-infected cells. Mucosal transmission of simian immunodeficiency virus (SIV) in non-human primates, and presumably of HIV in humans, can occur without epithelial-cell damage of the oral, rectal and genital mucosae $e^{6,84,89}$. HIV presents a daunting challenge to vaccinologists. It seems to exploit mucosal antigen-sampling mechanisms at these sites, including vesicular transepithelial transport pathways of $\mathrm{M}$ cells and uptake by intraepithelial DCs ${ }^{85,86}$. The mucosal tissues of the rectum and tonsils both contain abundant mucosal lymphoid follicles and associated $\mathrm{M}$ cells $\mathrm{s}^{33,87}$, and $\mathrm{M}$ cells provide a short and rapid pathway across the epithelial bar$\operatorname{rier}^{34,87}$. This could explain the observed transmission of HIV to adults through infected semen, or to babies through infected milk.

\section{Box 1 |Correlates of mucosal protection}

To guide the design of mucosal vaccine strategies, investigators have been hoping to define the 'correlates of mucosal protection'; that is, the concentrations, epitope specificities and locations of immune effectors that would be likely to protect most vaccinees during mucosal exposure to HIV. Attempts to define realistic correlates of mucosal protection through challenge studies in vaccinated non-human primates have been compromised by the use of large mucosal-challenge doses of highly infective SIV. Such challenges are intended to assure infection of most or all unvaccinated control animals after a single exposure, but might overwhelm the immune response elicited by the vaccine. New experimental models in which monkeys are repeatedly exposed to low doses of challenge virus through the rectum or vagina are more likely to identify effective mucosal vaccine candidates ${ }^{113}$. It is unlikely that exact quantitative correlates will be established for humans, given real-life disparities in exposure levels and local mucosal conditions. Nevertheless, there is evidence from highly exposed, uninfected subjects that HIV-specific cytotoxic T lymphocytes and mucosal IgA antibodies are associated with resistance to sexually transmitted HIV infection ${ }^{90,91}$.
Epithelial cells themselves are not productively infected by HIV, but they serve as gateways for the delivery of infectious HIV parasites to antigen-presenting DCs and macrophages. As mucosal antigen-presenting cells interact with local $\mathrm{CD}^{+} \mathrm{T}$ cells, they unwittingly infect and ultimately disable the very cells that are needed to mount an effective immune response. Infection of local target cells can occur rapidly after deposition of virus on mucosal surfaces ${ }^{86}$. However, dissemination of virus to regional lymph nodes and other tissues might be delayed for up to several days ${ }^{88,89}$, providing a window of opportunity for local control of the infection by mucosal immune effectors. In any case, whether transmitted mucosally or injected, HIV and SIV replicate preferentially in mucosal tissues, such as the intestinal mucosa, that are rich in $\mathrm{CD}^{+}$ $\mathrm{T}$ cells ${ }^{31,32}$. Therefore, the ultimate goals of anti-HIV vaccines should be first to interrupt mucosal transmission at its earliest stages, before the virus has crossed the epithelial barrier and infected its first target cell, and then to prevent the establishment of viral reservoirs in mucosal tissues.

To achieve these goals, HIV-specific vaccines must generate multiple immune effectors, including HIVenvelope-specific antibodies in mucosal secretions, and CTLs and neutralizing HIV-envelope-specific antibodies in the mucosa and circulation. Given what we know about the induction of mucosal immune responses, it is unlikely that injected HIV vaccines alone will induce the mucosal responses that are required. Although correlates of mucosal protection are not yet established (BOX 1), there is evidence from highly exposed, uninfected human subjects that mucosal HIV-specific CTLs and IgA antibodies in secretions are associated with resistance to sexually transmitted HIV infection $^{90,91}$. The challenge is to identify the key effectors that are required and then to design a vaccination strategy that induces them. Many candidate mucosal vaccines, adjuvants and delivery strategies have been tested in mice and found to induce mucosal (as well as systemic) HIV-specific humoral and cell-mediated immune responses ${ }^{6,782}$. However, only a minority of these strategies have been taken to the next preclinical step: testing immunogenicity and protective efficacy after mucosal vaccination of non-human primates (TABLE 2).

Evidence from non-human primates. Most of the vaccine formulations that have undergone preclinical testing in macaques were designed to induce antiviral CTLs rather than antibodies, and of these only a few have been evaluated specifically for their ability to generate CTLs in mucosal tissues (TABLE 2). Nevertheless, several studies have shown that local mucosal CTLs that are induced by mucosal immunization can reduce plasma viral loads after mucosal challenge $e^{82,92-95}$. For example, rectal but not parenteral vaccination with a cocktail of peptides derived from HIV envelope, SIV group-specific antigen (gag) and SIV polymerase induced specific CTLs in the colonic mucosa and resulted in a dramatic reduction in viraemia after rectal challenge with a pathogenic SHIV (chimeric SIV containing the HIV envelope glycoprotein $)^{92}$. Similarly, nasal but not intravenous administration of non-pathogenic SHIV in macaques 
Table 2 | Relative immunogenicity of vaccines administered by mucosal routes in non-human primates

Vaccine and vaccination route*
Prime Boost

Boost

\section{Adenovirus-SIV}

Nasal plus oral, then intratracheal

Attenuated SHIV

Nasal

Intravenous

Poliovirus1-SIV

Nasal

SIV p55 particles (with cholera toxin)

Oral

Nasal

HIV gp140

(with $\mathrm{mLT}$ )

Nasal

HIV/SIV peptides

Rectal (with mLT)

Subcutaneous (with Montanide 51)

DNA-SIV particles

Intradermal

Intradermal plus rectal

Intradermal plus rectal plus intramuscular

DNA-SHIV particles (with DNA encoding

IL-2-Ig fusion protein)

Nasal

None

Nasal

Oral

Nasal

Nasal
SIV gp120 (with MPL)

Intramuscular

Poliovirus2-SIV

SIV p55 particles (with cholera toxin)

gp140 and p55

(with MF-59)

Intramuscular

HIV/SIV peptides

Rectal (with $\mathrm{mLT}$ )

Subcutaneous (with Montanide 51)

DNA-SIV particles

Intradermal

Intradermal plus rectal

Intradermal plus rectal plus intramuscular

MVA-SHIV

Rectal

SIVmac251

Challenge virus
and challenge
route

HIV- or SIV-specific immune responses ${ }^{\ddagger}$ Cell-mediated

Colon- Blood rectum

SIVmac251

Rectal

SHIV89.6P

Rectal

Rectal

Humoral

$\begin{array}{lll}\text { Serum } & \text { Rectal } & \text { Vaginal } \\ \lg G & \lg A & \lg A\end{array}$

Protection $^{\S}$

Refs

Vaginal

None

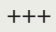

$++++/$

/ $\quad-\quad+$

61

57,121

$\begin{array}{llllll}\mathrm{ND} & ++ & ++++ & +++ & - & \mathrm{NA} \\ ++\rrbracket & ++ & ++++ & +++ & ++ & \mathrm{NA}\end{array}$

None

SHIVKu2

ND

$++$

$+++$

$+/-$

++++

NA

Rectal

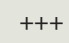

$++$

NA

NA

NA

$++++$

Rectal

ND

$++$

NA

NA

NA

SIVmac251

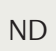

++
$+/-$
$+/-$

+
$+/-$
++

+/-
+++
$+/-$

NA

NA

NA

None

SHIV89.6P

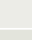

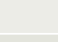

NA

*Vaccine adjuvants are indicated in parentheses. ${ }^{\ddagger}$ Immune responses are measured before challenge. These responses are based on median post-vaccination increases of: ++++, 25-100-fold; +++, 10-24.9-fold; ++, 5-9.9-fold; +, 2.5-4.9-fold in a majority of vaccine recipients; +/-, >2.5-fold in a minority of vaccine recipients;,$-<2.5$-fold in all vaccine recipients. In grading cellular immune responses, the results of all T-cell assays were considered. ${ }^{\S} \mathrm{Based}$ on the percentage of vaccinated animals that showed a lack of disease progression after challenge and reduction in plasma viraemia with sustained control. None, <20\%; $+/-, 20-39 \%$; ,$+ 40-59 \% ;++, 60-79 \% ;+++, 80-99 \% ;++++, 100 \%$. "This vaccine has induced sterilizing immunity in some animals. "In the small-intestinal lamina propria. Ig, immunoglobulin; IL-2, interleukin-2; mLT, mutant form of Escherichia coli heat-labile enterotoxin; MPL, monophosphoryl lipid A; MVA, modified vaccinia virus Ankara; NA, not applicable; ND, not determined; p55, HIV gag protein; SHIV, chimeric SIV with HIV envelope proteins; SIV, simian immunodeficiency virus.

was found to prevent disease after vaginal challenge with a heterologous pathogenic virus (SHIV89.6P) ${ }^{61}$. Priming of macaques by nasal administration of DNA encoding non-replicating SHIV89.6P particles, followed by boosting by nasal administration of modified vaccinia virus Ankara (MVA) expressing SHIV proteins, induced greater percentages of SHIV-specific $\mathrm{CD}^{+} \mathrm{T}$ cells in the rectum than in the blood and afforded significant protection against rectal challenge with SHIV89.6P ${ }^{94}$. In other studies, DNA-vaccine-mediated induction of SIV-specific CTLs (and antibodies) in the rectal mucosa was associated with protection against rectal challenge with heterologous virus ${ }^{95}$.

Until now, the greatest success in preventing mucosal transmission of immunodeficiency viruses has been achieved through the vaccination of macaques with live attenuated $\mathrm{SIV}^{96,97}$, which induces antiviral CTLs in the rectal and genital tract mucosa because of its ability to proliferate at these sites ${ }^{98}$. Live attenuated HIV is generally considered to be too risky for use as a human vaccine, but studies in monkeys have shown the advantages of using other live vectors for stimulating mucosal immunity (TABLE 2). For example, mucosally administered, recombinant SIV-expressing adenoviruses have been effective in preventing rectal transmission of highly pathogenic SIV in macaques, perhaps because adenovirus can replicate in intestinal tissues ${ }^{82}$. Nasal administration of vaccines, such as live non-pathogenic SHIVs or poliovirus that expresses SIV proteins in macaques, provided significant protection against mucosal SHIV or SIV transmission ${ }^{61,99}$. Although these data do not establish which of these various vaccine strategies is best, they have exploited our current 
knowledge about the regional nature of mucosal immune responses and have shown the protective potential of mucosal vaccines against HIV.

Secretory antibodies and protection against HIV. Prevention of HIV infection will clearly require specific antibodies ${ }^{100}$. HIV-specific serum antibodies might neutralize virus that has entered mucosal tissues by blocking the attachment and/or entry of virus to target cells ${ }^{100,101}$. On mucosal surfaces, secreted HIV-specific antibodies could provide an additional layer of protection by preventing virus from contacting mucosal surfaces, adhering to epithelial cells or crossing the epithelial barrier ${ }^{6}$. Indeed, large doses of vaginally administered gp120-specific monoclonal antibodies (denoted as b12) prevented vaginal SHIV transmission in macaques ${ }^{102}$. A few mucosally administered vaccines have elicited mucosal IgA antibodies in macaques (TABLE 2). However, the potential role of vaccine-induced secretory antibodies in protection against HIV or SIV has yet to be adequately tested. Meanwhile, studies using cultured monolayers of polarized epithelial cells have provided information about the interactions of HIV and HIVinfected cells with epithelial barriers and the specific antibodies capable of blocking these interactions. For adhering to mucosal surfaces, HIV uses receptors on epithelial cells that are distinct from the CD4 receptorchemokine co-receptor pairs that are required for the infection of target mononuclear cells. Although apical surfaces of epithelial cells in the rectum and female genital tract might contain the chemokine co-receptors CCR5 and CXC-chemokine receptor 4 (CXCR4) that might facilitate HIV transport ${ }^{103}$, they are CD4 negative ${ }^{104}$. However, epithelial-cell membranes contain galactosylceramide, a glycolipid that is recognized by a conserved region in the tip of the V3 loop of HIV gp120 (REF. 105) and by a highly conserved region (amino acids 650-668) in the gp41 ectodomain ${ }^{106}$. Transepithelial transport of HIV across cultured epithelia was inhibited by gp120specific or gp41-specific antibodies that prevented the
HIV-galactosylceramide interaction, but not by CD4specific antibodies ${ }^{107-110}$.

Clinical studies have sought to identify correlates of mucosal protection in humans (BOX 1). In several cohorts of HIV-uninfected people who were repeatedly exposed to HIV through sexual intercourse, resistance to infection was associated with serum and secretory IgA antibodies directed against the coiled-coil pocket region of gp41 (REF. 111). Although a few HIV-specific vaccines have been administered mucosally in human trials, so far none of these vaccines has resulted in measurable concentrations of HIV-specific secretory IgA ${ }^{112}$. However, it is important to note that these vaccines were not specifically designed for mucosal application, and the lack of mucosal immune response could be attributed to poor internalization of the vaccine at mucosal surfaces, the presence of pre-existing immunity against the vaccine vector used, and/or the lack of effective mucosal adjuvants.

\section{Concluding remarks}

Much has been learned from animal studies about the attributes of effective mucosal vaccines and the immune effectors that could function together to prevent and control mucosal transmission of HIV and other mucosally transmitted diseases. The current challenge is to apply this knowledge to vaccine design and to carry out collaborative, comparative clinical trials that systematically monitor all parameters of the immune response — humoral and cellular, mucosal and systemic - in serum, local secretions and mucosal tissues. Available data indicate that mucosal HIV vaccines should be particulate or live vectored, include components that alert the innate immune system, and include immunogenic, conserved forms of the envelope protein gp41 as well as gp120. Mucosal HIV vaccines would ideally be administered as part of a prime-boost strategy that induces both mucosal and systemic immunity. Much work remains to be done, but current research continues to clarify the concepts and provide the tools that are needed to exploit the full potential of mucosal vaccines.
1. Levine, M. M. Immunization against bacterial diseases of the intestine. J. Pediatr Gastroenterol. Nutr. 31, 336-355 (2000).

2. Lamm, M. E. Interactions of antigens and antibodies at mucosal surfaces. Annu. Rev. Microbiol. 51, 311-340 (1997).

3. Modlin, J. F. Poliomyelitis in the United States: the final chapter? JAMA 292, 1749-175 (2004).

4. Kapikian A. Z. et al. Efficacy of a quadrivalent rhesus rotavirus-based human rotavirus vaccine aimed at preventing severe rotavirus diarrhea in infants and young children. J. Infect. Dis. 174, S65-S72 (1996).

5. Belshe, R. B. et al. The efficacy of live attenuated cold-adapted, trivalent, intranasal influenza virus vaccine in children. N. Engl. J. Med. 338, 1405-1412 (1998).

6. Kozlowski, P. A. \& Neutra, M. R. The role of mucosal immunity in prevention of HIV transmission. Curr. Mol. Med. 3, 217-228 (2003).

7. Belyakov, I. M. \& Berzofsky, J. A. Immunobiology of mucosal HIV infection and the basis for development of a new generation of mucosal AIDS vaccines. Immunity 20, 247-253 (2004).

8. Neutra, M. R. \& Kraehenbuhl J. P. in Mucosal Immunology 3rd edn (eds Ogra, P. L. et al.) 111-130 (Academic Press, San Diego, 2005).
9. Brandtzaeg, P. et al. Regional specialization in the mucosal immune system: what happens in the microcompartments? Immunol. Today 20, 141-151 (1999).

10. van Egmond, M. et al. IgA and the IgA Fc receptor Trends Immunol. 22, 205-211 (2001).

11. Kagnoff, M. F. \& Eckmann, L. Epithelial cells as sensors for microbial infection. J. Clin. Invest. 100, S51-S55 (1997)

12. Izadpanah, A., Dwinell, M. B., Eckmann, L. Varki, N. M. \& Kagnoff, M. F. Regulated MIP-3 $\alpha /$ CCL20 production by human intestinal epithelium: mechanism for modulating mucosal immunity Am. J. Physiol. Gastroint. Liver Physiol. 280, G710-G719 (2001).

One of a series of studies by this group, documenting the signals produced by epithelial cells in response to microorganisms and their products.

13. MacDonald, T. T. \& Monteleone, G. Immunity, inflammation and allergy in the gut. Science 307, 1920-1925 (2005).

A timely review of the basic cellular mechanisms underlying common gastrointestinal diseases that are associated with dysfunction of the mucosal immune system.

14. Rakoff-Nahoum, S., Pagliano, J., Esalmi-Varzaneh, F., Edberg, S. \& Medzhitov, R. Recognition of commensal microflora by Toll-like receptors is required for intestinal homeostasis. Cell 118, 229-241 (2004). Recent evidence that TLR-mediated responses to non-pathogenic bacteria in the gut prevent local inflammation and are required for maintenance of a healthy epithelial barrier.

15 Backhed, F., Ley, R. E., Sonnenburg, J. L, Peterson, D. A. \& Gordon, J. I. Host-bacterial mutualism in the human intestine. Science 307 1915-1920 (2005).

A fascinating overview of our long and intimate symbiotic relationship with commensal intestinal bacteria.

16. Kozlowski, P. A., Cu-Uvin, S., Neutra, M. R. \& Flanigan, T. P. Comparison of the oral, rectal, and vaginal immunization routes for induction of antibodies in rectal and genital tract secretions of women. Infect. Immun. 65, 1387-1394 (1997).

17. Kozlowski, P. A. et al. Differential induction of mucosal and systemic antibody responses in women after nasal, rectal, or vaginal immunization: influence of the menstrual cycle. J. Immunol. 169, 566-574 (2002). A detailed description of methods for analysis of antibodies in human secretions, and the influence of vaccination site on local antibody production.

18. Mestecky, J., Moro, I., Kerr, M. A. \& Woof, J. M in Mucosal Immunology, 3rd edn (eds Ogra, P. L. et al.) 153-182 (Academic Press, San Diego, 2005). 
19. Kaetzel, C. S., Robinson, J. K., Chintalacharuvu, K. R. Vaerman, J. P. \& Lamm, M. The polymeric immunoglobulin receptor (secretory component) mediates transport of immune complexes across epithelial cells: a local defense function for IgA. Proc. Natl Acad. Sci. USA 88, 8796-8800 (1991).

20. Hutchings, A. B., Helander, A., Silvey, K. J. Lucas, W. T. \& Neutra, M. R. Secretory IgA antibodies against the $\sigma 1$ outer capsid protein of reovirus type 1 Lang prevent infection of mouse Peyer's patches. J. Virol. 78, 947-957 (2004).

21. Robinson, J. K., Blanchard, T. G., Levine, A. D. Emancipator, S. N. \& Lamm, M. E. A mucosal IgA-mediated excretory immune system in vivo. J. Immunol. 166, 3688-3692 (2001).

22. Black, K. P., Cummins, J. E. \& Jackson, S. Serum and secretory IgA from HIV-infected individuals mediate antibody-dependent cellular cytotoxicity. Clin. Immunol. Immunopathol. 81, 182-190 (1996).

23 Eriksson, K. et al. Specific-antibody-secreting cells in the rectums and genital tracts of nonhuman primates following vaccination. Infect. Immun. 66, 5889-5896 (1998).

24. Kutteh, W. H., Mestecky, J. \& Wira, C. R. in Mucosal Immunology, 3rd edn (eds Ogra, P. L. et al.) 1631-1646 (Academic Press, San Diego, 2005).

25 Parr, E. L. \& Parr, M. B. Immunoglobulin G is the main protective antibody in mouse vaginal secretions after vaginal immunization with attenuated herpes simplex virus type 2. J. Virol. 71, 8109-8115 (1997).

26. Kozlowski, P. A. et al. Modified wick method using Weck-Cel sponges for collection of human rectal secretions and analysis of mucosal HIV antibody. J. Acquir. Imm. Defic. Syndr. 24, 297-309 (2000)

27. Yoshida, M. et al. Human neonatal Fc receptor mediates transport of IgG into luminal secretions for delivery of antigens to mucosal dendritic cells Immunity 20, 769-783 (2004).

28. Mantis, N. J. et al. Selective adherence of immunoglobulin A to murine Peyer's patch M Cells: evidence for a novel IgA receptor. J. Immunol. 169, 1844-1851 (2002)

29. Corthesy, B. et al. A pathogen-specific epitope inserted into recombinant secretory immunoglobulin is immunogenic by the oral route. J. Biol. Chem. 52, 33670-33677 (1996)

30. Belyakov, I. M. et al. The importance of local mucosal HIV-specific CD8 ${ }^{+}$cytotoxic T lymphocytes for resistance to mucosal viral transmission in mice and enhancement of resistance by local administration of IL-12. J. Clin. Invest. 102, 2072-2081 (1998).

31. Veazey, R. S. \& Lackner, A. A. Getting to the guts of HIV pathogenesis. J. Exp. Med. 200, 697-700 (2004).

A review of the predilection of HIV and SIV for the intestinal mucosa and implications for pathogenesis and vaccines.

32. Brenchley, J. M. et al. CD4+ $\mathrm{T}$ cell depletion during all stages of HIV disease occurs predominantly in the gastrointestinal tract. J. Exp. Med. 200, 749-759 (2004).

33. O'Leary, A. D. \& Sweeney, E. C. Lymphoglandular complexes of the colon: structure and distribution Histopathology 10, 267-283 (1986).

34. Neutra, M. R., Mantis, N. J. \& Kraehenbuhl, J.-P. Collaboration of epithelial cells with organized mucosal lymphoid tissues. Nature Immunol. 2, 1004-1009 (2001).

35. Cook, D. N. et al. CCR6 mediates dendritic cell localization, lymphocyte homeostasis, and immune responses in mucosal tissue. Immunity 12, 495-503 (2000).

36. Iwasaki, A. \& Kelsall, B. L. Localization of distinct Peyer's patch dendritic cell subsets and their recruitment by chemokines macrophage inflammatory protein (MIP)-3 $\alpha$, MIP-3 $\beta$, and secondary lymphoid organ chemokine. J. Exp. Med. 191, 1381-1394 (2000).

An excellent analysis of the DCs of Peyer's patches, and their functions in the specialized microcompartments within organized mucosal lymphoid tissues.

37. Zhao, X. et al. CCL9 is secreted by the follicleassociated epithelium and recruits dome region Peyer's patch $\mathrm{CD} 11 \mathrm{~b}+$ dendritic cells. J. Immunol. 171, 2797-2803 (2003).

38. Hopkins, S. A., Niedergang, F., Corthesy-Theulaz, I. E. \& Kraehenbuhl, J. P. A recombinant Salmonella typhimurium vaccine strain is taken up and survives within murine Peyer's patch dendritic cells. Cell. Microbiol. 2, 59-68 (2000)
39. Shreedhar, V. K., Kellsall, B. L. \& Neutra, M. R Cholera toxin induces migration of dendritic cells from the sub-epithelial dome region to T and B cel areas of Peyer's patches. Infect. Immun. 71, 504-509 (2003).

40. Iwasaki, A. \& Kelsall, B. Unique functions of CD $11 b^{+}$ $\mathrm{CD} 8 \alpha^{+}$, and double negative Peyer's patch dendritic cells. J. Immunol. 166, 4884-4890 (2001).

41. MacPherson, G. G. \& Liu, L. M. Dendritic cells and Langerhans cells in the uptake of mucosal antigens. Curr. Top. Microbiol. Immunol. 236, 33-53 (1999).

42. Holt, P. G., Schon-Hegrad, M. A. \& McMenamin, P. G. Dendritic cells in the respiratory tract. Int. Rev. Immunol. 6, 139-149 (1990).

43. Miller, C. J., McChesney, M. \& Moore, P. F. Langerhans cells, macrophages and lymphocyte subsets in the cervix and vagina of rhesus macaques. Lab. Invest. 67, 628-634 (1992).

44. Niess, J. H. et al. CX3CR1-mediated dendritic cell access to the intestinal lumen and bacterial clearance. Science 307, 254-258 (2005)

Identification of a novel mechanism for migration of DCs into the intestinal epithelium.

45. Fagarasan, S. \& Honjo, T. Intestinal IgA synthesis: regulation of front-line body defences. Nature Rev. Immunol. 3, 63-72 (2003).

Evidence for a mechanism whereby local IgA production can be rapidly increased during a mucosal memory response.

46. Mayer, L. \& Shao L. Therapeutic potential of oral tolerance. Nature Rev. Immunol. 4, 407-419 (2004)

47. Belyakov, I. M., Hammond, S. A., Ahlers, J. D. Glenn, G. M. \& Berzofsky, J. A. Transcutaneous immunization induces mucosal CTLs and protective immunity by migration of primed skin dendritic cells. J. Clin. Invest. 113, 998-1007 (2004). Some nice detective work explaining how immunization through the skin can result in mucosal immune responses.

48. Kunkel, E. J. \& Butcher, E. C. Plasma-cell homing. Nature Rev. Immunol. 3, 822-829 (2003).

49. Mora, J. R. et al. Selective imprinting of gut-homing T cells by Peyer's patch dendritic cells. Nature $\mathbf{4 2 4}$. 88-93 (2003).

50. Mestecky, J. The common mucosal immune system and current strategies for induction of immune responses in external secretions. J. Clin. Immunol. 7, 265-276 (1987)

51. Hieshima, K et al. CC chemokine ligands 25 and 28 play essential roles in intestinal extravasation of IgA antibody-secreting cells. J. Immunol. 173 3668-3675 (2004)

52. Lindholm, C., Naylor, A., Johansson, E. L. Quiding-Jarbrink, M. Mucosal vaccination increases endothelial expression of mucosal addressin cell adhesion molecule 1 in the human gastrointestinal tract. Infect. Immun. 7, 1004-1009 (2004).

53. Stagg, A. J., Kamm, M. A. \& Knight, S. C. Intestinal dendritic cells increase T cell expression of $\alpha_{4} \beta_{7}$ integrin. Eur. J. Immunol. 32, 1445-1454 (2002)

54. Haddad, W. et al. P-selectin and P-selectin glycoprotein ligand 1 are major determinants for T 1 cell recruitment to nonlymphoid effector sites in the intestinal lamina propria. J. Exp. Med. 198, 369-377 (2003)

55. Qimron, U. et al. Non-replicating mucosal and systemic vaccines: quantitative and qualitative differences in the $\mathrm{Ag}$-specific CD8 ${ }^{+} \mathrm{T}$ cell population in different tissues. Vaccine 22, 1390-1394 (2004).

56. Staats, H. F., Montgomery, S. P. \& Palker, T. J. Intranasal immunization is superior to vaginal, gastric, or rectal immunization for induction of systemic and mucosal anti-HIV antibody responses. AIDS Res. Hum. Retroviruses 13, 945-952 (1997).

57. Imaoka, K. et al. Nasal immunization of nonhuman primates with simian immunodeficiency virus p55gag and cholera toxin adjuvant induces $T_{H} 1 / T_{H} 2$ help for virus-specific immune responses in reproductive tissues. J. Immunol. 161, 5952-5958 (1998).

58. Rudin, A., Riise, G. \& Holmgren, J. Antibody responses in the lower respiratory tract and male urogenital tract in humans after nasal and oral vaccination with cholera toxin B subunit. Infect. Immun. 67, 2884-2890 (1999).

59. Gallichan, W. S. \& Rosenthal, K. L. Long-term immunity and protection against herpes simplex virus type 2 in the murine female genital tract after mucosal but not systemic immunization. J. Infect. Dis. 177 , 1155-1161 (1998)
60. Egan, M. A. et al. Immunogenicity of attenuated vesicular stomatitis virus vectors expressing HIV type 1 Env and SIV Gag proteins: comparison of intranasal and intramuscular vaccination routes. AIDS Res. Hum. Retroviruses 20, 989-1004 (2004).

61. Enose, Y. et al. Protection by intranasal immunization of a nef-deleted, nonpathogenic SHIV against intravaginal challenge with a heterologous pathogenic SHIV. Virology 298, 306-316 (2002)

62. Belyakov, I. M. et al. Mucosal immunization with HIV-1 peptide vaccine induces mucosal and systemic cytotoxic T lymphocytes and protective immunity in mice against intrarectal recombinant HIV-vaccinia challenge. Proc. Natl Acad. Sci. USA. 95, 1709-1714 (1998).

63. Ryan, E. J., Daly, L. M. \& Mills, H. G. Immunoregulators and delivery systems for vaccination by mucosal routes. Trends Biotechnol. 19, 293-304 (2001).

A review of mucosal adjuvants and strategies to increase the uptake of antigens into mucosal tissues.

64. Jones, B. D., Ghori, N. \& Falkow, S. Salmonella typhimurium initiates murine infection by penetrating and destroying the specialized epithelial $\mathrm{M}$ cells of the Peyer's patches. J. Exp. Med. 180, 15-23 (1994).

65. Sicinski, P. et al. Poliovirus type 1 enters the human host through intestinal M cells. Gastroenterology 98, 56-58 (1990)

66. Seong, S. Y., Cho, N. H., Kwon, I. C. \& Jeong, S. Y. Protective immunity of microsphere-based mucosal vaccines against lethal intranasal challenge with Streptococcus pneumoniae. Infect. Immun. 67 3587-3592 (1999).

67. Baca-Estrada, M. E., Foldvari, M., Babiuk, S. L. \& Babiuk, L. A. Vaccine delivery: lipid-based delivery systems. J. Biotechnol. 83, 91-104 (2000).

68. Chabot, S. et al. A novel intranasal Protollin-based measles vaccine induces mucosal and systemic neutralizing antibody responses and cell-mediated immunity in mice. Vaccine 23, 1374-1383 (2005)

69. McNeela, E. A. et al. A mucosal vaccine against diptheria: formulation of crossreacting material (CRM97) of diptheria toxin with chitosan enhances local and systemic antibody and $\mathrm{T}_{2} 2$ responses following nasal delivery. Vaccine 19, 1188-1198 (2000).

70. Frey, A. et al. Role of the glycocalyx in regulating access of microparticles to apical plasma membranes of intestinal epithelial cells: implications for microbial attachment and oral vaccine targeting. J. Exp. Med. 184, 1045-1060 (1996)

71. Mantis, N. J., Frey, A. \& Neutra, M. R. Accessibility of glycolipid and oligosaccharide epitopes on rabbit villus and follicle-associated epithelium. Am. J. Physio . Gastrointest. Liver Physiol. 278, G915-G923 (2000).

72. Choi, W. S., Pal-Ghosh, R. \& Morrow, C. D. Expression of human immunodeficiency virus type 1 (HIV-1) gag, pol, and env proteins from chimeric HIV-1-poliovirus minireplicons. J. Virol. 65, 2875-2883 (1991).

73. Tacket, C. O., Sztein, M. B., Losonsky, G. A., Wasserman, S. S. \& Estes, M. K. Humoral, mucosal, and cellular responses to oral Norwalk virus-like particles in volunteers. Clin. Immunol. 108, 241-247 (2003).

74. Haneberg, B., Herland Berstad, A. K. ¿ Holst, J. Bacteria-derived particles as adjuvants for non-replicating nasal vaccines. Adv. Drug Deliv. Rev. 51, 143-147 (2001)

75. Elson, C. O. \& Dertzbaugh, M. T. Mucosal adjuvants. in Mucosal Immunology 3rd Edn. (eds Ogra, R. et al.) 967-986 (Academic Press, New York, 2005).

76. van Ginkel, F. W., Jackson, R. J., Yuki, Y. \& McGhee, J. R. The mucosal adjuvant cholera toxin redirects vaccine proteins into olfactory tissues. J. Immunol. 165, 4778-4782 (2000).

77. Mutsch, M. et al. Use of the inactivated intranasal influenza vaccine and the risk of Bell's palsy in Switzerland. N. Engl. J. Med. 350, 896-903 (2004).

78. Lycke, N. From toxin to adjuvant: basic mechanisms for the control of mucosal IgA immunity and tolerance. Immunol. Lett. 97, 193-198 (2005).

A review of the promise and problems of bacterial enterotoxins as mucosal adjuvants, and description of a new approach.

79. Belyakov, I. M., Ahlers, J. D., Clements, J. D., Strober, W. \& Berzofsky, J. A. Interplay of cytokines and adjuvants in the regulation of mucosal and systemic HIV-specific CTL. J. Immunol. 165, 6454-6462 (2000). 
80. Gallichan, W. S. et al. Intranasal immunization with $\mathrm{CpG}$ oligodeoxynucleotides as an adjuvant dramatically increases IgA and protection against herpes simplex virus- 2 in the genital tract. J. Immunol. 166, 3451-3457 (2001).

81. McSorley, S. J., Ehst, B. D., Yu, Y. \& Gewirtz, A. T. Bacterial flagellin is an effective adjuvant for CD4 ${ }^{+} \mathrm{T}$ cells in vivo. J. Immunol. 169, 3914-3919 (2002).

82. Malkevitch, N. \& Robert-Guroff, M. A call for replicating vector prime-boost strategies in HIV vaccine design. Expert Rev. Vaccines 4, S105-S117 (2004).

An extensive review of studies using live and non-living viral and bacterial vectors, and various systemic and mucosal vaccine strategies, to induce anti-HIV immune responses in monkeys.

83. Lemiale, F. et al. Enhanced mucosal immunoglobulin A response of intranasal adenoviral vector human immunodeficiency virus vaccine and localization in the central nervous system. J. Virol. 77, 10078-10087 (2003).

84. Milman, G. $\&$ Sharma, O. Mechanisms of HIV/SIV mucosal transmission. AIDS Res. Human Retroviruses 10, 1305-1312 (1994)

85. Amerongen, H. M. et al. Transepithelial transport of HIV- 1 by intestinal M cells: a mechanism for transmission of AIDS. J. Acquir. Immune Defic Syndr. 4, 760-765 (1991).

$86 \mathrm{Hu}, \mathrm{J}$. Gardner M. B. \& Miller C. J. Simian immunodeficiency virus rapidly penetrates the cervicovaginal mucosa after intravaginal inoculation and infects intraepithelial dendritic cells. J. Virol. 74 , 6087-6095 (2000)

87. Fujimura, $\mathrm{Y}$. Evidence of $\mathrm{M}$ cells as portals of entry for antigens in the nasopharyngeal lymphoid tissue of humans. Virchows Arch. 436, 560-566 (2000).

88. Spira, A. I. et al. Cellular targets of infection and route of viral dissemination after an intravaginal inoculation of simian immunodeficiency virus into rhesus macaques. J. Exp. Med. 183, 215-225 (1996).

89. Zhang, Z.-O. et al. Sexual transmission and propagation of SIV and HIV in resting and activated CD4+ T cells. Science 286, 1353-1357 (1999).

90. Mazzoli, S. et al. HIV-specific mucosal and cellular immunity in HIV-seronegative partners of HIVseropositive individuals. Nature Med. 3, 1250-1257 (1997).

91 Kaul R et al. New insights into HIV-1 specific cytotoxic T-lymphocyte responses in exposed, persistently seronegative Kenyan sex workers. Immunol. Lett. 79, 3-13 (2001)

92. Belyakov, I. M. et al. Mucosal AIDS vaccine reduces disease and viral load in gut reservoir and blood after mucosal infection of macaques. Nature Med. 7, 1320-1326 (2001)

93. Mäkitalo, B. et al. Enhanced cellular immunity and systemic control of SHIV infection by combined parenteral and mucosal administration of a DNA prime MVA boost vaccine regimen. J. Gen. Virol. 85, 2407-2419 (2004)

94. Bertley, F. M. N. et al. Control of simian/human immunodeficiency virus viremia and disease progression after IL-2-augmented DNA-modified vaccinia virus ankara nasal vaccination in nonhuman primates. J. Immunol. 172, 3745-3757 (2004).

95. Fuller, D. H. et al. Induction of mucosal protection against primary, heterologous simian immunodeficiency virus by a DNA vaccine. J. Virol. 76, 3309-3317 (2002).
96. Nilsson, C. et al. Live attenuated simian immunodeficiency virus (SIV)mac in macaques can induce protection against mucosal infection with SIVsm. AIDS 12, 2261-2270 (1998).

97. Tenner-Racz, K et al. Early protection against pathogenic virus infection at a mucosal challenge site after vaccination with attenuated simian immunodeficiency virus. Proc. Natl Acad. Sci. USA 101, 3017-3022 (2004)

98. Cromwell M. A. et al. Induction of mucosal homing virus-specific $C D 8+T$ lymphocytes by attenuated simian immunodeficiency virus. J. Virol. 74 8762-8766 (2000)

99. Crotty, S. et al. Protection against simian immunodeficiency virus vaginal challenge by using Sabin poliovirus vectors. J. Virol. 75, 7435-7452 (2001). This paper reports the exploitation of a viral vector that naturally invades organized mucosal lymphoid tissues to deliver SIV genes and induce partial protection against subsequent mucosal challenge.

100. Burton, D. R. Antibodies, viruses, and vaccines. Nature Rev. Immunol. 2, 706-713 (2002). A thorough discussion of the potential importance of antibodies and their mechanisms of action in prevention and control of HIV.

101. Parren, P. W. H. I. et al. Antibody protects macaques against vaginal challenge with a pathogenic R5 simian/human immunodeficiency virus at serum levels giving complete neutralization in vitro. J. Virol. 75, 8340-8347 (2001).

102. Veazey, R. S. et al. Prevention of virus transmission to macaque monkeys by a vaginally applied monoclonal antibody to HIV-1 gp 120. Nature Med. 9, 1-4 (2003).

103. Fotopoulos, G. et al. Transepithelial transport of HIV-1 by M cells is receptor mediated. Proc. Natl Acad. Sci. USA 99, 9410-9414 (2002).

104. Janoff, E. N. \& Smith, P. D. Emerging concepts in gastrointestinal aspects of HIV-1 pathogenesis and management. Gastroenterology 120, 607-621 (2001).

105. Fantini, J. et al. Synthetic and soluble analogues of galactosylceramide (GalCer) bind to the V3 domain of HIV-1 gp120 and inhibit HIV-1-induced fusion and entry. J. Biol. Chem. 272, 7245-7252 (1997).

106 Alfsen, A. \& Bomsel, M. HIV-1 gp41 envelope residues $650-685$ exposed on native virus act as a lectin to bind epithelial cell galactosyl ceramide. J. Biol. Chem. 277, 25649-25659 (2002)

107. Bomsel, M. Transcytosis of infectious human immunodeficiency virus across a tight human epithelial cell line barrier. Nature Med. 3, 42-47 (1997).

108. Alfsen, A., Iniguez, P., Bouguyon, E. \& Bomsel, M. Secretory IgA specific for a conserved epitope on gp41 envelope glycoprotein inhibits epithelial transcytosis of HIV-1. J. Immunol. 166, 6257-6265 (2001).

109. Hocini, H. et al. High-level ability of secretory IgA to block HIV type 1 transcytosis: contrasting secretory IgA and IgG responses to gp 160. AIDS Res. Hum. Retroviruses 13, 1179-1185 (1997).

110. Matoba, N. et al. A mucosally targeted subunit vaccine candidate eliciting HIV-1 transcytosis blocking antibodies. Proc. Natl Acad. Sci. USA 101, 13584-13589 (2004)

111 Clerici, M. et al. Serum IgA of HIV-exposed uninfected individuals inhibit HIV through recognition of a region within the $\alpha$-helix of gp41. AIDS 16,1731-1741 (2002)

112. Wright, P. F. et al. Comparison of systemic and mucosal delivery of 2 canarypox virus vaccines expressing either HIV-1 genes or the gene for rabies virus G protein. J. Infect. Dis. 189, 1221-1231 (2004).
113. McDermott, A. B. et al. Repeated low-dose mucosal simian immunodeficiency virus SIVmac239 challenge results in the same viral and immunological kinetics as high-dose challenge: a model for the evaluation of vaccine efficacy in nonhuman primates. J. Virol. 78, 3140-3144 (2004).

114. Wassén, L., Schön, K., Holmgren, J., Jertborn, M. \& Lycke, N. Local intravaginal vaccination of the female genital tract. Scand. J. Immunol. 44, 408-414 (1996).

115. Rudin, A., Johansson, E.-L., Bergquist, C. \& Holmgren, J. Differential kinetics and distribution of antibodies in serum and nasal and vaginal secretions after nasal and oral vaccination of humans. Infect. Immun. 66, 3390-3396 (1998).

116. Quiding, M. et al. Intestinal immune responses in humans: oral cholera vaccination induces strong intestinal antibody responses and interferon- $\gamma$ production and evokes immunological memory. J. Clin. Invest. 88, 143-148 (1991).

117. Kantele, A. et al. Differences in immune responses induced by oral and rectal immunizations with Salmonella typhi Ty21a: evidence for compartmentalization within the common mucosal immune system in humans. Infect. Immun. 66 5630-5635 (1998).

118. Forrest, B. D., Shearman, D. J. C. \& LaBrooy, J. T. Specific immune responses in humans following delivery of live typhoid vaccine. Vaccine 8, 209-212 (1990).

119. Ogra, P. L. \& Karzon, D. T. Distribution of poliovirus antibody in serum, nasopharynx and alimentary tract following segmental immunization of lower alimentary tract with poliovaccine. J. Immunol. 102, 1423-1430 (1969).

120. Ogra, P. L. \& Ogra, S. S. Local antibody response to poliovaccine in the human female genital tract. J. Immunol. 110, 1307-1311 (1973)

121. Kubota, M. et al. Oral immunization with simian immunodeficiency virus p5 $5^{\text {gag }}$ and cholera toxin elicits both mucosal IgA and systemic IgC immune responses in nonhuman primates. J. Immunol. 158, 5321-5329 (1997).

22. Vajdy, M. et al. Mucosal and systemic anti-HIV responses in rhesus macaques following combinations of intranasal and parenteral immunizations. AIDS Res. Hum. Retroviruses 20, 1269-1281 (2004).

123. Wang, S.-W. et al. Effective induction of simian immunodeficiency virus-specific systemic and mucosal immune responses in primates by vaccination with proviral DNA producing intact but noninfectious virions. J. Virol. 74, 10514-10522 (2000).

Acknowledgements

The authors' laboratories are supported by National Institutes of Health (NIH) research grants HDI7557 and AI58896, and by NIH Center grant DK34854.

Competing interests statement

The authors declare no competing financial interests.

DATABASES

The following terms in this article are linked online to: Entrez Gene: http://www.ncbi.nlm.nih.gov/entrez/query. fcgi?db=gene

$\alpha \beta_{7}|\mathrm{CCL} 9| \mathrm{CCL} 20|\mathrm{CCL} 28| \mathrm{CCR} 1|\mathrm{CCR} 5| \mathrm{CCR} 6|\mathrm{CCR} 10|$ CXCR4 | HIV |IL-12 | MADCAM1

Access to this interactive links box is free online. 